\title{
A APLICAÇÃO DA EXPERIMENTAÇÃO CONTEXTUALIZADA E INTERDISCIPLINAR COM ESTUDANTES DO ENSINO MÉDIO: PERCEPÇÕES E CONSIDERAÇÕES
}

\author{
Anelise Grünfeld de Luca ${ }^{1}$ \\ José Claudio Del Pino²
}

\section{Resumo}

A experimentação tem papel importante na aprendizagem, desde que concebidas com o propósito de favorecer o diálogo em sala de aula e a contextualização dos conteúdos. O objetivo deste artigo é divulgar uma pesquisa que visou investigar a efetividade da experimentação contextualizada e interdisciplinar apresentada no livro: "Dialogando Ciência entre sabores odores e aromas: contextualizando os alimentos química e biologicamente", analisando-se a realização dos experimentos possibilitam aprendizado numa perspectiva dialógica e problematizadora. A abordagem experimental se deu nas aulas de Biologia em três turmas de $1^{\circ}$ ano de Ensino Técnico Integrado ao Ensino Médio. Os estudantes em grupos realizaram e apresentaram os experimentos; após, responderam um questionário. A partir da análise dos dados, considerou-se a importância da indissociabilidade da teoria e prática, valorizando as concepções prévias dos estudantes e confrontando-as com os discursos da ciência. Destaca-se a inserção do diálogo na dinâmica da experimentação através dos questionamentos, da contextualização e da interdisciplinaridade.

Palavras-chave:Experimentação. Contextualizada. Interdisciplinaridade. Ensino Médio.

\begin{abstract}
Experimentation has an important role in learning, if they are designed with the purpose of favoring dialogue in the classroom and the contextualization of the contents. The objective of this research is to investigate the effectiveness of contextualized and interdisciplinary experimentation presented in the book: "Dialogando Ciência entre sabores, odores e aromas: contextualizing the foods chemically and biologically (DC)", analyzing whether the realization of the experiments enables learning in a dialogical and problematizing perspective. The experimental approach took place in biology classes in three classes from the 1st year of Technical Education Integrated to

\footnotetext{
${ }^{1}$ Doutora em Educação em Ciências: Química da Vida e Saúde, pelo Instituto Federal Catarinense. Docente do Instituto Federal Catarinense - Campus Araquari. E-mail: anelise.luca@gmail.com

${ }^{2}$ Doutor em Engenharia de Biomassa, pela Universidade Federal do Rio Grande do Sul, e pós-doutor, pela Universidade de Aveiro-Portugal. Professor associado da Universidade Federal do Rio Grande do Sul.

E-mail: delpinojc@yahoo.com.br
} 
High School. Students in groups carried out and presented the experiments; after they answered a questionnaire. From the analysis of the data, it was considered the importance of the inseparability of theory and practice, valuing the students' previous conceptions and confronting them with the discourses of science. We highlight the insertion of dialogue in the dynamics of experimentation through questioning, contextualization and interdisciplinarity.

Keywords: Experimentation. Contextualized. Interdisciplinarity. High School.

\section{Introdução}

A experimentação no ensino tem sido defendida por professores e estudantes, devido ao seu caráter motivador e na aquisição de habilidades de laboratório. E, então, surge um questionamento: este seria o motivo para realização da experimentação? Caamaño (2010) apresenta e discute o porquê realizar trabalhos práticos e afirma que

Los trabajos prácticos constituyen una de las actividades más importantes en la enseñanza de las ciencias por permitir una multiplicidad de objetivos: la familiarización, observación e interpretación de los fenómenos que son objeto de estudio en las clases de ciencias, el contraste de hipótesis en los procesos de modelización de la ciencia escolar, el aprendizaje del manejo de instrumentos y técnicas de laboratorio y de campo, la aplicación de estrategias de investigación para la resolución de problemas teóricos y prácticos y, en definitiva, la comprensión procedimental de la ciencia. (CAAMAÑO, 2010, p. 95).

Contudo, pesquisadores como Hodson (1989) têm apresentado um conjunto de "interferências" relacionadas ao modo como as atividades experimentais são utilizadas e integradas no ensino e questiona se realmente contribuem para a apropriação do conhecimento a nível conceitual e procedimental. Quanto ao caráter motivador da experimentação, Hodson (1989) discute que esta sentença seria válida se o trabalho prático fosse excitante e interessante, possibilitando que os estudantes investigassem suas proposições e provocassem a curiosidade, no sentido da exploração das ideias, confrontando-as ao problema a ser pesquisado, diferentemen- 
te do que geralmente é proposta, a experimentação para a simples coleta de dados.

Caamaño (1992) defende que, além da motivação, outro fator importante deve ser considerado, tendo em vista a experimentação investigativa, o sentimento de confiança na capacidade de resolver problema durante a realização das investigações práticas.

[...] el carácter motivador de estas actividades y su influencia en la creación de hábitos de trabajo (rigurosidad, espíritu de colaboración, etc) a valorar el sentimiento de confianza en la capacidad para resolver problemas que genera en los estudiantes la realización de investigaciones prácticas que pueden ser resueltas con éxito. (CAAMAÑO, 1992, p. 63).

Em se tratando da aquisição de habilidades de laboratório, Hodson (1989) questiona se tais habilidades têm valor educativo, e advoga que é necessária uma sólida argumentação a favor da escolha crítica daquelas que devem ser ensinadas e o esclarecimento aos estudantes que estas habilidades de laboratório são proveitosas para outras atividades. Além desses aspectos, Hodson (1989) apresenta outras críticas quanto ao uso da experimentação: a certeza de que favorece a aprendizagem de conceitos científicos, a promoção do método científico e o desenvolvimento de certas atitudes cientificas. E, sobre tais aspectos, argumenta que os estudantes não podem adquirir novos conceitos por meio dos experimentos sem que lhes seja apresentado devidamente o suporte teórico, para ele as considerações teóricas devem preceder a investigação experimental.

Este autor também salienta que existe uma crença de que os estudantes poderiam se interessar pelas atividades dos cientistas a partir da adoção dos procedimentos utilizados por eles, isto caracterizaria atitudes científicas. Ainda, conclui que a forma como os trabalhos práticos são desenvolvidos e conduzidos pelos professores, podem apresentar resultados positivos e efetivos na aprendizagem de conceitos científicos, na compreensão da natureza da ciência e na aquisição de atitudes científicas. 
A aplicação da experimentação contextualizada e interdisciplinar com estudantes do Ensino Médio

Isto nos provoca a pensar sobre a importância do planejamento das atividades experimentais e o tipo de experimentação que o professor utilizará em suas aulas. Caamaño (2010) explicita a importância de o professor ter clareza que a efetividade da aprendizagem, mediante os trabalhos práticos, depende dos objetivos que se pretende e estes dependem da concepção de ciência e de como se aprende ciências. Galiazzi e Gonçalves $(2004$, p. 327) reiteram que é importante considerar no planejamento "[...] a possibilidade de enriquecer o conhecimento sobre a natureza da ciência, pois esse conhecimento influencia a aprendizagem dos estudantes na atividade experimental".

E, então, vale considerar a forma como a experimentação é desenvolvida em sala de aula com o intuito de propiciar o aprendizado dos estudantes. Hodson (1989) salienta que a forma impensada com que os professores têm utilizado o trabalho prático tem gerado insatisfação, no sentido de solucionar os problemas de aprendizagem. Faz-se necessário refletir como abordar a experimentação considerando o ensino e aprendizagem de conceitos científicos.

Caamaño (1992) relaciona os trabalhos práticos ${ }^{3}$ com diversos modelos didáticos, atentando para a forma como a experimentação é abordada nas salas de aula, o autor designa a expressão paradigma para cada uma das abordagens. Primeiramente, o Paradigma do ensino por transmissão ${ }^{4}$, identificado tradicionalmente pelos trabalhos práticos utilizados para desenvolver habilidades como: manipulação de aparatos, técnicas de laboratório, ilustração e comprovação de leis cientificas.

Outro Paradigma do descobrimento orientado influenciado pela visão difundida nos anos 70 em que os trabalhos práticos consistiam em atividades de descobrimento de conceitos, leis, mediante o uso dos processos das ciências orientado pelo professor. Também existe uma con-

\footnotetext{
${ }^{3}$ Trabalho prático para este autor é classificado em: ilustrativos, informativos, investigativos, uso de habilidades básicas e atividades de observação.

${ }^{4}$ A expressão foi grifada para destacar cada uma das concepções apresentadas por Caamaño (1992).
} 
A aplicação da experimentação contextualizada e interdisciplinar com estudantes do Ensino Médio

cepção mais autônoma em que se colocava ênfase nas conclusões dos conceitos que se pretende alcançar, no próprio processo de investigação, Paradigma do descobrimento autônomo.

Em outra concepção consideram-se os trabalhos práticos como atividades encaminhadas para aprender os processos da ciência (observação, elaboração de hipóteses, realização de investigação, isto é, o método científico) independentemente dos conteúdos conceituais concretos sobre o que se trabalhava, qual seja, o Paradigma dos processos da ciência. A partir da concepção construtivista de ensino e aprendizagem das ciências, ocorreram mudanças na abordagem da experimentação, valorizando o conhecimento prévio dos estudantes e a construção dos conceitos num processo de interação de ideias, constituindo o Paradigma de investigações com finalidades teóricas.

Tomando como base a teoria da Aprendizagem Significativa de Ausubel, os trabalhos práticos receberam um novo olhar frente à aquisição de habilidades práticas e com vista à resolução de problemas práticos, caracterizando o Paradigma de investigação unido a resolução de problemas práticos. Os diversos paradigmas, apresentados por Caamaño (1992), enfatizam a influência dos modelos didáticos nas abordagens da experimentação, evidenciando a importância de o professor ter clareza no tipo de experimentação que quer realizar, evitando a predominância de um deles. Assim, Caamaño (1992) explicita que

Se defiende la necesidad de disponer de un esquema integrador de los diferentes tipos de trabajo práctico, resituando muchas de sus funciones en una perspectiva constructivista y comprensiva del aprendizaje. [...] se considera que una concepción equilibrada de la enseñanza de las ciencias requiere un uso diversificado de los diferentes trabajos prácticos tipificados, lo cual significa, teniendo en cuenta la situación de la que partimos, aumentar el trabajo investigativo en las programaciones de los cursos de ciencias. (CAAMAÑO, 1992, p. 1). 
A aplicação da experimentação contextualizada e interdisciplinar com estudantes do Ensino Médio

Sabe-se que, na formação inicial dos professores, é muito incipiente a abordagem da experimentação no ensino, geralmente a ênfase está na aplicação do método científico e na racionalidade científica, favorecendo, assim, a visão simplista de que a experimentação por si só possibilitaria comprovar as teorias científicas. De Boer, (1991 apud Izquierdo et al. 1999, p. 45) observa isso, quando discute que alguns professores de Química introduziram uma inovação muito importante, converteram o laboratório em aula por excelência para a aprendizagem da Química, "considerando que los alumnos sólo podrian comprender las teorías científicas si ellos mismos reproducían los experimentos cruciales; es decir, que los alumnos sólo entenderían los conceptos científicos haciendo de científicos".

Acredita-se que a experimentação tem papel importante na aprendizagem, desde que concebidas com o propósito de favorecer o diálogo em sala de aula e a contextualização dos conteúdos. Galiazzi e Gonçalves (2004) apresentam características positivas a serem incorporadas no desenvolvimento das atividades experimentais, "como a inserção do diálogo em sala de aula como modo de favorecer a explicitação do conhecimento e construção de argumentos validados no grupo na interlocução teórica e prática." (GALIAZZI, GONÇALVES, 2004, p, 331).

De fato, o diálogo que acontece no grupo que está realizando os experimentos proporciona as ideias de cada participante, na busca por explicações para os resultados obtidos, na construção de argumentos contribuindo para a autonomia e a socialização das teorias pessoais.

Algo significativo a considerar sobre a experimentação é o que Galiazzi e Gonçalves (2004) explicitam como argumento favorável, o fato de as atividades experimentais serem instrumentos do discurso das ciências, permitindo a enculturação dos estudantes e professores, à medida que

[...] possam aprender não só as teorias das Ciências, entre eles a Química, mas também como se constrói o conhecimento cien- 
A aplicação da experimentação contextualizada e interdisciplinar com estudantes do Ensino Médio

tífico em um processo de questionamento, discussão de argumentos e validação desses argumentos por meio do diálogo oral e escrito, com uma comunidade argumentativa que começa na sala de aula, mas a transcende. (GALIAZZI, GONÇALVES, 2004, p. 331).

Considerando as discussões pautadas neste texto, apresenta-se a experimentação contextualizada e interdisciplinar abordada no livro: " $D i$ alogando Ciência entre sabores odores e aromas: contextualizando os alimentos Quimica e biologicamente" (DC), que tem como objetivo proporcionar a integração, a reflexão e a discussão de conceitos inerentes à Biologia e a Química por meio do contexto dos alimentos. Esta proposta vem sendo aplicada em diversas situações: em aulas de ciências do Ensino Fundamental, Biologia e Química do Ensino Médio.

Os experimentos são tratados de forma dialogada entre a Química e a Biologia, os materiais são de fácil aquisição e manuseio, não exigem um laboratório especializado, permitindo que possam ser realizados em escolas que não contemplam um espaço próprio para tal. Os questionamentos presentes nas atividades experimentais consideram os conhecimentos prévios dos estudantes, para que o professor possa prosseguir suas aulas conhecendo o que sabem sobre o assunto, buscando a argumentação e a validação mediante o que é conhecido pela ciência. Ainda a proposta evidencia, em espaço do livro, o que é denominado Aprofunde seus conhecimentos... Onde estão expostos textos de diversos autores e gêneros textuais que objetivam a promoção da leitura, da escrita e da pesquisa. As possibilidades de utilização dos experimentos pelo professor são abertas para que possa dentro de seu contexto escolar e curricular realizá-los e explorá-los.

A partir dos pressupostos teóricos abordados até aqui, foi desenvolvida uma pesquisa com estudantes do $1^{\circ}$ ano do Ensino Médio, quanto à efetividade da experimentação contextualizada e interdisciplinar apresentada no livro DC, no sentido de analisar e compreender de que forma as interações entre a realização dos experimentos e o entendimento dos 
A aplicação da experimentação contextualizada e interdisciplinar com estudantes do Ensino Médio

conceitos científicos envolvidos possibilitam aprendizado numa perspectiva dialógica e problematizadora.

\section{Caminhos percorridos: a pesquisa}

O desenvolvimento desta pesquisa se deu nas aulas de Biologia, em três turmas de $1^{\circ}$ ano de Ensino Técnico Integrado ao Ensino Médio, totalizando 112 estudantes. Inicialmente, os estudantes foram divididos em grupos e receberam um experimento do livro DC, para realizarem e apresentarem para toda a turma.

Os experimentos realizados foram relacionados com a composição química e a ação biológica dos alimentos. Os estudantes verificaram o grau de insaturação dos óleos por meio do teste do iodo; a presença e quantidade de glicose nos alimentos utilizando a glicofita; a identificação das proteínas mediante o teste do biureto; ação das enzimas (bromelina e papaína) na digestão das proteínas; identificação da vitamina $\mathrm{C}$ e presença dos sais minerais (cálcio e ferro) nos alimentos.

Após receberem as instruções de como realizar os experimentos, os estudantes, em contraturno no laboratório da escola, executaram-nos, seguindo as recomendações do professor; apresentaram em sala de aula e discutiram os resultados obtidos; em outra aula, responderam um questionário com dez questões, sendo nove abertas e uma fechada, mensurada através da escala Likert (ELLIOT, 2012).

No entanto, para este artigo se apresentará e discutirá as respostas dos estudantes para quatro questões abertas, objetivando perceber, por meio do desenvolvimento dos experimentos, os entendimentos dos estudantes quanto à efetividade da experimentação contextualizada e interdisciplinar. Ressalta-se que somente 17 estudantes responderam às referidas questões. As questões que serão analisadas estão apresentadas no quadro 1. 
A aplicação da experimentação contextualizada e interdisciplinar com estudantes do Ensino Médio

Quadro 1: Questões elaboradas para a pesquisa com os estudantes

1. De que forma essa abordagem experimental auxiliou na compreensão do assunto estudado em Biologia?

2. Em sua opinião, os questionamentos que aparecem no transcorrer dos experimentos, favorecem a discussão dos conceitos químicos e biológicos envolvidos? Explique.

3. Em sua opinião, a realização de experimentos é algo importante, imprescindivel ou desnecessário para o aprendizado. Justifique.

4. A proposta experimental do livro tem como concepção a interdisciplinaridade (Química e Biologia) e a contextualização (alimentos). Em sua opinião isto é importante, imprescindivel ou desnecessário? Justifique.

Esta investigação está inserida na perspectiva da pesquisa qualitativa, que valoriza e explicita a interpretação dos diferentes significados presentes nos resultados. As informações obtidas foram analisadas mediante a metodologia de Análise Textual Discursiva apresentada por Moraes e Galiazzi, (2011, p. 11) “[...] a intenção é a compreensão, reconstruir conhecimentos existentes sobre temas investigados". Apresentam-se, a seguir, as categorias construídas na interpretação dos dados, considerando as respostas dos estudantes para as questões do quadro 1, que foram: a importância da teoria aliada a prática; dinâmica da experimentação: relevância do diálogo e da leitura; a experimentação como algo importante para o aprendizado e a relevância da experimentação contextualizada e interdisciplinar.

\section{A importância da teoria aliada à prática}

De modo geral, as respostas dos estudantes, para a primeira questão, evidenciaram a importância da teoria que apresentada pelo professor em sala de aula deva estar acompanhada por atividades experimentais que auxiliem os entendimentos dos conteúdos conceituais abordados nas 
A aplicação da experimentação contextualizada e interdisciplinar com estudantes do Ensino Médio

aulas curriculares, possibilitando a relação do fazer e do pensar, como se pode observar nas seguintes respostas 5 :

"[...] vendo os resultados na prática foi mais fácil o entendimento de tudo que aprendemos em aula, pois aprofundamos mais nosso conhecimento tendo que ler e entender o que estamos fazendo."

"[...] os alunos podem ver o conteúdo na prática, assim tendo uma assimilação melhor com matéria." (2)

"[...] é que mais fácil entender olhando e analisando os resultados a sua frente do que escutar o professor falando e tentando imaginar." (3)

As atividades experimentais devem permitir a articulação entre os fenômenos e as teorias, buscando sempre uma relação constante entre o fazer e o pensar. "A explicação de um fenômeno utilizando-se de uma teoria é o que denominamos de relação teoria-experimento, ou seja, é a relação entre o fazer e o pensar." (SILVA, MACHADO, TUNES, 2010, p. 236). $\mathrm{E}$, é a relação teoria-experimento que se pretende quando se propõe a experimentação, onde os estudantes possam participar efetivamente, considerando o ensinar e o aprender como processos indissociáveis. Quando se faz o uso da teoria para explicar um fenômeno se está testando a capacidade de generalização e de previsão desta teoria, e é isto pode conferir à experimentação no ensino um caráter investigativo.

A participação dos estudantes se deu desde a organização dos materiais até a execução dos experimentos, a maioria não havia realizado experimentação antes, nem mesmos nas aulas de Química e, desafiados, se posicionaram frente aos assuntos anteriormente abordados pelo professor em sala de aula e, então, puderam observar como as reações acontecem na prática. Evidencia-se, nas respostas apresentadas a seguir, que

\footnotetext{
${ }_{5}^{5}$ Optou-se por destacar as respostas dos estudantes em itálico e entre aspas. Cada resposta está indicada por um número, identificando o estudante.
} 
A aplicação da experimentação contextualizada e interdisciplinar com estudantes do Ensino Médio

os estudantes relacionaram à teoria apresentada em sala de aula com o que foi observado e discutido durante a experimentação, indissociando a teoria-experimento:

"[...] Podemos entender como as enzimas presentes em nosso corpo realizam as reações necessárias para a melhor absorção de nutrientes." (4)

"[...] ajudou a compreender como as reações Químicas atuam em nosso corpo e são essenciais para as nossas vidas e funcionamento de nossos copos." (5)

Nesta outra resposta, pode se perceber que, para este estudante, a experimentação favoreceu o entendimento e o esclarecimento do assunto estudado:

"[...] a abordagem experimental nos ajuda a compreender melhor por que nos estávamos vendo as reações Químicas. Tem algumas coisas que em sala de aula são um tanto confusas de entender e através de experimentos foram esclarecidas e puderam ser melhor entendidas." (6)

Concorda-se, aqui, com Rosito (2000) enquanto discorre em seu artigo sobre "O ensino de ciências e a experimentação", afirma que:

[...] as atividades experimentais não devem ser desvinculadas das aulas teóricas, das discussões em grupo e de outras formas de aprender. O que foi exposto em aula e o que foi obtido no laboratório precisa se constituir como algo que se complementa. $[\ldots]$ as atividades experimentais realizadas sem integração com uma fundamentação teórica não passam de ativismo. (ROSITO, 2000, p. 197).

Diante dessas respostas, pode-se perceber que, para uma melhor apreensão da relação teoria-experimento, faz-se necessário que o professor planeje e conduza as atividades experimentais adequadamente, considerando o contexto, permitindo maior interação e envolvimento dos es- 
A aplicação da experimentação contextualizada e interdisciplinar com estudantes do Ensino Médio

tudantes como protagonistas deste aprendizado. A observação realizada, durante a experimentação, provocou a busca por respostas e estas foram possiveis recorrendo à teoria abordada em sala de aula, justificando aquilo que o professor apresentou em aula. "Portanto, em todas as observações são as teorias que possibilitam uma interpretação e não o contrário." (GALIAZZI, GONÇALVES, 2004, p. 327).

\section{Dinâmica da experimentação: relevância do diálogo e da leitura}

Uma das características favoráveis da experimentação é o diálogo proporcionado entre os estudantes e isto é verificado mediante os questionamentos, do professor e da própria observação do experimento. Então, surgem as explicitações do conhecimento do estudante através de argumentações e problematizações do ocorrido, favorecendo a identificação das concepções prévias, permitindo a inserção do professor na interpretação do fenômeno observado a um nível mais teórico, partindo do que o estudante já sabe.

Diante das respostas para a segunda questão elucidada no quadro 1, foi possivel perceber que os questionamentos provocaram a leitura, a curiosidade e a reflexão, atitudes positivas para a aprendizagem, demonstradas nas seguintes respostas:

"[...] pois as questões buscam respostas especificas que nos fazem ler e reler e pensar no que foi feito no experimento para ter uma boa resposta." (1)

"[...] porque quando descobrimos. Falamos algo em uma discussão é muito mais fácil de se lembrar e aprender por essa participação." (2)

"[...] porque são justamente as dúvidas que mais nos fazem pensar e nos deixam curiosos com o porque de aquilo ocorrer. São através das dúvidas e questionamentos que temos de saber mais $e$ ir atrás do resultado." (3) 
A aplicação da experimentação contextualizada e interdisciplinar com estudantes do Ensino Médio

"[...] pois com o questionamento, vem perguntas, com perguntas, vem respostas e, com respostas, vem aprendizado que fica mais fácil de aprender." (4)

É possivel constatar nas respostas a necessidade de ler, reler, pensar, discutir para se chegar a uma conclusão sobre o questionamento proposto na experimentação. Os questionamentos provocaram atitudes de busca, participação seja através da leitura, da discussão e do confronto de ideias. Nessa perspectiva, o conhecimento expresso pelos estudantes em uma experimentação sempre é um indicativo de aprendizagem, pois se constitui uma forma do professor conhecer o que pensam como articulam as ideias sobre aquele fenômeno e como se apropriam dos discursos da ciência.

\section{A experimentaçãocomo algo importante para o aprendizado}

No terceiro questionamento feito aos estudantes foi possivel constatar que a maioria dos que responderam afirmou que a realização da experimentação é importante para o aprendizado. As justificativas estão apresentadas a seguir:

"[...] é importante, pois a prática facilita muito mais o aprendizado do que apenas teoria." (1)

"[...] Importante os resultados que não conseguimos ver, se mostram visiveis nas experiências." (2)

“[...] É algo muito importante, por que o melhor jeito de aprender é experimentando e fazendo por nós mesmos sem dúvida é difícil de esquecer das aplicações práticas que nós mesmos fazemos $e$ verificamos." (3) 
A aplicação da experimentação contextualizada e interdisciplinar com estudantes do Ensino Médio

"[...] É algo importante, pois nos ajuda a entender o assunto de uma forma melhor e com menos tensão." (4)

“[...] Importante. Primeiramente pra uma melhor concentração e para sair da rotina básica do livro do escolar, é bom pra um aprendizado prático e não somente teórico." (5)]

"[...] foi importante, pois ajudou no aprendizado por que saiu da rotina." (6)

Verifica-se que, para os estudantes, a importância da experimentação está no entendimento da teoria, na observação do fenômeno, na diversificação das aulas tornando mais atrativas e menos monótonas. Algo significativo também é o fazer, o fato do estudante poder manipular, vivenciar aquela experimentação, constitui-se uma marca na sua aprendizagem: "[...] o melhor jeito de aprender é experimentando e fazendo por nós mesmos sem dúvida é dificil de esquecer das aplicações práticas que nós mesmos fazemos e verificamos". Essa constatação também se reporta ao desenvolvimento da autonomia do estudante e no sentimento de confiança na capacidade de realizar o experimento.

Em outras respostas, encontram-se explícitas as ideias bem pontuais quando ao assunto abordado: alimentos. Na primeira resposta descrita abaixo, identifica-se um posicionamento frente às escolhas de um cidadão, sendo um dos propósitos do livro DC; na outra o estudante relaciona com os conteúdos tratados em sala de aula, a importância dos alimentos.

“[... É importante para compreensão do funcionamento do organismo. Muitas vezes, ajuda até a adotarmos hábitos mais saudáveis por entender o que alimentos ruins poderiam causar." (7)

"[...] Importante. Ajuda a provar e ver o que realmente acontece com as reações Químicas que há em nossos corpos e como os alimentos ajudam nestas." (8) 
A aplicação da experimentação contextualizada e interdisciplinar com estudantes do Ensino Médio

Nesta outra resposta, o estudante relaciona com uma qualidade de um bom professor a realização de experimentos.

“[...] em vez de só ter teoria que não pode faltar é claro, mas o bom professor de Biologia é aquele que de vez em quando faz uma aula no laboratório para fazer e observar os resultados obtidos." (9)

Ainda é possivel verificar que a experimentação não é algo que o estudante considera fundamental, tendo em vista que uma boa aula teórica também alcançaria os mesmos resultados.

“[...] Importante, mas não necessário, ajudam o aluno a entender o assunto, mas uma boa aula teórica também chega lá." (10)

"[...] Não é obrigatório, todavia ajuda a deixar o conhecimento mais instigante mais legal mais prático." (11)

Os relatos apresentados nessas duas respostas concordam com o que Hodson (1989) apresenta de que existem outras formas de promover a aprendizagem e mais eficazes do que a experimentação.

\section{A relevância da experimentação contextualizada e interdisciplinar}

Quando os estudantes foram questionados sobre a proposta experimental do livro, a maioria considerou importante a experimentação contextualizada e interdisciplinar, explicitando a relevância dos conhecimentos apresentados em cada uma das áreas; estes estudantes conseguiram delimitar o objeto de estudo da Química e da Biologia, conforme as respostas a seguir:

"[...] Importante, pois entendemos melhor todos os processos quimicos e biológicos com eles por testarmos os experimentos entender a ação dos reagentes e entender melhor o funcionamento do 
A aplicação da experimentação contextualizada e interdisciplinar com estudantes do Ensino Médio

organismo e das coisas cotidianas relacionadas a processos biológicos." (1)

"[...] É importante, pois permite conhecer mais sobre algo do cotidiano (alimento) através da Biologia (ajuda a entender o que esse alimento vai influenciar nosso corpo) e como que isso ocorre (Quimica)." (2)

$\mathrm{E}$, em outras respostas, pode-se inferir que o contexto abordado no livro DC foi percebido pelos estudantes, considerando-o positivo para o entendimento do cotidiano:

"[...] importante situa-nos sobre quais alimentos são necessários para um bom funcionamento de nossos corpos." (3)

“[...] É importante, pois são coisas que estão ao nosso redor." (4)

"[...] É importante por que nos ajuda a compreender as coisas do nosso dia a dia e os assuntos de diferentes matérias da escola." (5)

"[...] Importante a globalidade e assimilação com coisas do cotidiano realmente aumenta a compreensão." (6)

"[...] na vista do professor o livro pode ser mais fácil pois ele pode apenas falar respondam tal coisa e me entreguem, mas no ponto de vista dos alunos a prática principalmente com alimentos ajudou na melhora dos estudos e acho que foi importante." (7)

A contextualização dos conteúdos já é preconizada pelos documentos oficiais como a Lei de Diretrizes e Bases e os Parâmetros Curriculares Nacionais e tem consequência direta no aprendizado do estudante, pois o insere no mundo em que vive em situações reais do uso das substâncias e de suas implicações. Vale ressaltar que a inserção do cotidiano no ensino não pode ser encarada como uma simples menção, apresentando onde se encontram aquelas substâncias ou onde aparece aquele fenômeno, 
mas buscando problematizar, dentro de um olhar diferenciado e não reducionista sobre o cotidiano, procurando extrair dele suas características comuns, corriqueiras para estudo mais complexo embasado em conhecimentos sistematizados (LUTFI, 1988; 1992).

Nas próximas respostas se observa que os estudantes entenderam o sentido mais amplo da interdisciplinaridade apresentada no livro DC, o diálogo entre as áreas de Biologia e Química:

"[...] É importante, pois mostra que nenhuma disciplina pode ter total eficiência trabalhando sozinha." (8)

"[...] Para mim seria importante, pois a Quimica e a Biologia fazem parte da nossa vida junto com alimento." (9)

“[...] É necessário por que é mais um jeito científico de começar a ver as coisas." (10)

"[...] É importante, pois ajuda a entender duas matérias que não se podem ver." (11)

Considerando que os contextos são muitos e que, para dar conta, os conteúdos de Química são insuficientes, então se faz necessário a inserção de conceitos de outras áreas do conhecimento, explicitado por Silva, Machado e Tunes (2010, p. 245): “[...] Esse novo olhar sobre as atividades experimentais proporciona uma visão mais ampla dos fenômenos, revelando a complexidade da vida moderna e possibilitando a diversidade de abordagens".

\section{Considerações finais}

A partir da análise dos dados, pode-se considerar a importância da indissociação da teoria e prática, valorizando as concepções prévias dos estudantes e confrontando-as com os discursos da ciência. E, então, se destaca a inserção do diálogo na dinâmica da experimentação por meio 
dos questionamentos propostos pelo professor em seu planejamento e nas atividades experimentais, favorecendo a investigação. $\mathrm{Na}$ construção de argumentos que respondam a estes questionamentos, ressalta-se a leitura e a discussão em grupo como forma de validação das teorias pessoais, colaborando para a autonomia e a socialização do conhecimento.

A contextualização e a interdisciplinaridade são importantes para os entendimentos dos diversos fenômenos nos quais estão inseridos os estudantes, como cidadãos. Acredita-se que a experimentação no ensino deve ser abordada e problematizada nos cursos de formação inicial e continuada de professores para que se possa discutir e se fundamentar teoricamente, superando a visão simplista, de que, através da experimentação, se chega às teorias estabelecidas nas Ciências, comprovando-as.

Em contrapartida, a experimentação, quando bem planejada, considerando a vivência do estudante, a discussão em grupo, a autonomia e a tomada de decisão, a leitura, a escrita, o diálogo entre as áreas do conhecimento e o diálogo, como explicitação das ideias dos estudantes, constitui-se uma estratégia que favorece o aprendizado. Concorda-se com Galiazzi e Gonçalves (2004, p. 331) quando apresentam "[...] a experimentação como um instrumento de explicitação de teorias; de enculturamento no discurso científico, [...] de enriquecimento das teorias pessoais que integram outros conhecimentos além do conhecimento científico".

\section{Referências}

CAAMAÑO, A. Aula de innovación educativa. [Versión electrónica]. Revista Aula de Innovación Educativa, n. 9, p. 61-68, 1992.

. Los trabajos prácticos en Ciencias. In: ALEIXANDRE, M. P. J. (coord.). Enseñar Ciencias. 4. ed. Barcelona: Editorial GRAO, 2010.

ELLIOT, L. G. (Org). Instrumentos de avaliação e pesquisa: caminhos para construção e validação. Rio de Janeiro: WAK, 2012. 
A aplicação da experimentação contextualizada e interdiscipfinar com estudantes do Ensino Médio

GALIAZZI, M. do C.; GONÇALVES, F. P. A natureza pedagógica da experimentação: uma pesquisa na Licenciatura em Química. Química Nova,v. 27, n. 2, p. 326-331, 2004.

HODSON, D. Uma visão crítica em relação ao trabalho prático nas aulas de ciências (Tradução e adaptação de Andréa Horta Machado de: HODSON, D. A critical look at pratical work in school science. School Science Review, v. 71, n. 256, p. 33-40, mar. 1990.)

IZQUIERDO, M; SANMARTÍ, N; ESPINET, M. Fundamentación y diseño de las prácticas escolares de ciencias experimentales. Enseñanza de las Ciencias, v. 17, n.1, p. 45-60, 1999.

LUTFI, M. Cotidiano e educação em Química: os aditivos em alimentos como proposta para o ensino de Química no 2ºu. Ijuí: Unijuí, 1988.

. Ferrados e cromados: produção social e apropriação privada do conhecimento químico. Ijuí: Unijuí, 1992

MORAES, R.; GALIAZZI, M. do C. Análise Textual Discursiva. 2. ed. rev. Ijuí: Editora Unijuí, 2011.

ROSITO, B. A. O ensino de ciências e a experimentação. In: MORAES, R. Construtivismo e ensino de Ciências: reflexões epistemológicas e metodológicas. Porto Alegre: EDIPUCRS, 2000.

SILVA, R. R.; MACHADO, P. F. L.; TUNES, E. Experimentar sem medo de errar. In: SANTOS, L. P. dos; MALDANER, O. A. (orgs). Ensino de Química em Foco. Ijuí: Editora Unijuí, 2010. 